\title{
CUIDADOS METODOLÓGICOS NO ESTUDO DA HISTÓRIA DO DIREITO DE PROPRIEDADE
}

\author{
Sérgio Said Staut Jr*
}

\begin{abstract}
RESUMO: A obra "Senhores e Caçadores", de Edward Thompson, proporciona um excelente exemplo da formação da noção moderna de propriedade. Demonstra o valor que começa a assumir, na Inglaterra dos séculos XVII e XVIII, um espaço fechado ou um objeto delimitado de uso e gozo exclusivo, praticamente absoluto e restrito de um senhor, denominado proprietário, sujeito de direito. Partindo desse interessante relato histórico, o presente trabalho analisa alguns cuidados metodológicos no estudo da história do direito de propriedade a partir das reflexões do historiador italiano Paolo Grossi.
\end{abstract}

\section{SENHORES E CAÇADORES: UM CASO PARADIGMÁTICO}

Edward P. Thompson, um dos maiores historiadores do século XX, na sua importante obra "Senhores e Caçadores", analisa entre outras questões a história de uma lei na Inglaterra do século XVIII. ${ }^{1}$ Com a aprovação

* Mestre em Direito pela UFPR e Doutorando em Direito das Relações Sociais na área de História do Direito no Programa de Pós-Graduação da Faculdade de Direito da UFPR. Professor e Advogado.

${ }^{1}$ Deve ser observado que Edward Thompson em "Senhores e Caçadores" vai muito além da observação histórica de uma lei, o autor por meio da reconstrução de vários acontecimentos que marcaram o percurso da Lei Negra analisa o que representou o século XVIII na Inglaterra e o próprio papel do direito naquele período histórico. dessa lei em maio de 1723 , denominada "9 George I c. 22", que ficou conhecida como "A Lei Negra", ${ }^{2}$ foram criados mais de cinqüenta novos delitos capitais.

A "Lei Negra" foi elaborada com o intuito, ou pretexto, de proteger as florestas e os bosques ingleses contra os "caçadores clandestinos" e evitar "desordens sociais" que vinham ocorrendo especialmente nas

\footnotetext{
2 Essa lei foi denominada de "A Lei Negra" em "homenagem" aos caçadores das florestas inglesas que, para capturarem de maneira mais fácil os animais selvagens, especialmente os servos (gamos ou veados), utilizavam o artifício de pintar os rostos de negro, geralmente com carvão, ficando assim camuflados. (THOMPSON, E. P. Senhores e Caçadores. 2.ed. Rio de Janeiro: Paz e Terra, 1989).
} 
regiões em torno das Florestas de Windsor e de Hampshire.

Em virtude da amplitude e abrangência da "Lei Negra", que extrapolava em muito a simples defesa das florestas inglesas e a contenção dos distúrbios sociais, dificilmente uma conduta criminosa não poderia ser encaixada nessa nova lei. ${ }^{3}$

Conforme relata Thompson, o "principal conjunto de infrações era a caça, ferimento ou roubo de gamos ou veados, e a caça ou pesca clandestina de coelhos, lebres e peixes."4 Todas essas infrações eram "passíveis de morte se os infratores estivessem armados e disfarçados, e, no caso dos cervos, se os delitos fossem cometidos em qualquer floresta real, ou estivessem os delinqüentes armados ou não. Outros delitos referiam-se à destruição da cabeceira ou outeiro de qualquer lago piscoso; ao abate ou mutilação dolosa de cabeças de gado; à derrubada de árvores 'plantadas em qualquer aléia ou em crescimento em qualquer jardim, pomar ou plantação'; ao ateamento de fogo a qualquer casa, celeiro, meda de feno etc.; a disparos dolosos contra qualquer pessoa; ao envio de cartas anônimas exigindo 'dinheiro, veação ou qualquer outra coisa de valor'; e ao resgate

\footnotetext{
3 Thompson observa que, apesar da nova lei prever em torno de cinqüenta delitos capitais, um "cálculo mais rigoroso, porém mais legalista, considerando as diversas categorias de pessoas a cometer cada infração (armadas ou não, disfarçadas ou não, principais responsáveis em primeiro ou segundo grau, cúmplices etc.), resulta num total de 200 a 250 delitos. Além do mais, a Lei estava esboçada de modo tão vago que se converteu em terreno prolífico para decisões judiciais cada vez mais abrangentes." (THOMPSON, E. P. Senhores $e$ Caçadores..., p. 23).
}

${ }^{4}$ THOMPSON, E. P. Senhores e Caçadores... p. 22. à força de qualquer pessoa presa por qualquer um desses delitos." 5

Assim, a simples caça sem autorização de um animal na floresta, mesmo que para comer; a destruição da cabeceira de um lago piscoso; a derrubada de uma árvore ou a coleta de lenha numa região não permitida; ou o fato da pessoa ser encontrada armada ou disfarçada vagando por uma floresta, são alguns exemplos de crimes punidos com a pena de morte pela "Lei Negra".

Em virtude tanto de "sua severidade como pelo caráter frouxo e indiscriminado do seu esboço, a Lei não tinha precedentes. Fornecia um versátil arsenal de morte adequado para a repressão de muitas formas de distúrbio social."

Além disso, a "Lei Negra" serviu, em grande medida, aos interesses dos proprietários, especialmente à oligarquia Whig, ${ }^{7}$ que adquiriram, com essa nova lei, um importante instrumento legal não apenas de defesa de suas propriedades "imóveis" (propriedades rurais, parques, florestas e a própria casa) e de suas propriedades "móveis" (gado, animais selvagens, lenha, turfa etc.), mas, conforme observa Thompson, um meio para a consolidação da noção moderna de propriedade como um, ou talvez "o" direito natural, absoluto, exclusivo e inviolável.

5 THOMPSON, E. P. Senhores e Caçadores... p. 22.

6 THOMPSON, E. P. Senhores e Caçadores... p. 247.

${ }^{7}$ Nas palavras de Thompson: "Certamente tentei mostrar, na evolução da Lei Negra, uma expressão da ascendência de uma oligarquia Whig, que criou novas leis e distorceu antigas formas legais, a fim de legitimar sua propriedade e status próprios;" (THOMPSON, E. P. Senhores e Caçadores... p. 351). 
Qualquer perturbação ao sagrado direito de propriedade deveria ser punida com a morte.

Ressalta-se, ainda, que os acontecimentos envolvendo a "Lei Negra" demonstraram o papel, inúmeras vezes, desempenhado pelos Estados Modernos na defesa da propriedade privada. Como ensina Thompson, "O Estado britânico, concordavam todos os legisladores do século 18, existia para preservar a propriedade e, incidentalmente, as vidas e liberdades dos proprietários (...) [e] talvez nenhum acontecimento tenha contribuído tanto para acostumar a mentalidade das pessoas a esse método de Estado do que a aprovação de 9 George I c. 22, que veio a ser conhecida como 'A Lei Negra de Waltham' ou simplesmente, 'A Lei Negra". 8

Entretanto, um dos temas mais importantes abordadas no livro, e esse é um ponto fundamental do presente trabalho, é a questão do embate entre direitos ou, talvez, um conflito entre concepções de mundo profundamente diversas. Nesse ponto, a "Lei Negra" parece ser um caso emblemático não apenas do século XVIII, mas de toda a história da Modernidade.

Em uma passagem de "Senhores e Caçadores" a mudança dos tempos e do direito resta expressa com muita clareza e, por isso, deve ser ressaltada: "Sob alguns aspectos, o século 18 demonstrou uma tolerância: homens e mulheres não eram mais mortos ou torturados, por suas opiniões ou crenças religiosas, como feiticeiros ou heréticos; políticos destituídos não mais subiam ao cadafalso. Mas, a cada decênio, definiam-se mais e mais invasões da propriedade como delitos capitais.". 9 Bruxas e feiticeiros não eram mais torturados e queimados na Europa civilizada, eram os crimes contra a propriedade que mandavam as pessoas à forca. Eis a evolução e humanização do direito moderno.

Como demonstra de forma muito interessante Thompson, a história da "Lei Negra" é uma história complexa. A reconstrução histórica realizada pelo autor e sua análise atestam que as relações conflitantes e os direitos envolvidos naquele período abrangiam muito mais do que um simples conflito entre delinqüentes (caçadores) e proprietários (senhores), em um contexto marcado por uma lei rigorosa e injusta. Em "Senhores e Caçadores" observa-se, de certa maneira, a passagem e o embate de concepções feudais de pertencimento para uma visão moderna em matéria de propriedade e de sua regulação jurídica. Parece ser possível falar em ruptura.

Em "Senhores e Caçadores" observar-se uma disputa entre os direitos e costumes feudais envolvendo diferentes relações de pertencimento e o direito moderno abstrato e "universal" de propriedade privada, de caráter individual e exclusivo, que estava em ampla expansão e consolidação não apenas na Inglaterra do século XVIII. Segundo Thompson, o "que muitas vezes estava em questão não era a propriedade defendida pela lei contra a não-propriedade; eram outras definições dos direitos de propriedade; para o proprietário de terras, o fechamento das terras comunais; para o trabalhador rural, os direitos comunais; para os funcionários das florestas, 'terrenos preservados' para os

\footnotetext{
${ }^{8}$ THOMPSON, E. P. Senhores e Caçadores... p. 21.
} 
servos; para os habitantes da floresta, o direito de apanhar torrões de grama."10

Para os trabalhadores rurais, para os moradores da floresta, bem como para as pessoas acostumadas a retirar o seu sustento do campo e das florestas, romper com alguns costumes e tradições feudais representava uma séria violação aos direitos preservados e protegidos por inúmeras gerações. Não respeitar as antigas posses e ocupações costumeiras, impedir pessoas da região de residir, cortar madeira, pegar galhos, apanhar turfa, recolher madeira e caçar nas "suas" florestas, significava uma clara ruptura com o direito até então vigente naquelas regiões.

Conforme observado, diferentes direitos e diferentes fundamentações, uma disputa de, pelo menos, dois grandes períodos históricos. Mas não era só isso, existiam também outros interesses em jogo. Não era apenas aos proprietários que interessava a "Lei Negra". Como relata Thompson, existia naquele período toda uma burocracia que cuidava ou pelo menos deveria cuidar das florestas, mas que em realidade utilizava as suas prerrogativas e os seus poderes em benefício próprio, apropriando-se privativamente dos bens extraídos dos parques e das florestas do Rei. Além disso, essa lei fornecia aos governantes um forte instrumento (legislativo) para a repressão de qualquer perturbação ou revolta social.

Sem dúvida, a obra "Senhores e Caçadores", de Edward Thompson, proporciona um excelente exemplo da formação da noção moderna de propriedade. Demonstra o valor

10 THOMPSON, E. P. Senhores e Caçadores... p. 351 . que começa a assumir, na Inglaterra dos séculos XVII e XVIII, um espaço fechado ou um objeto delimitado de uso e gozo exclusivo, praticamente absoluto e restrito de um senhor, denominado proprietário, sujeito de direito. ${ }^{11}$ Thompson verifica, ainda, através desse caso concreto, a mudança de direitos e o papel desempenhado pela nova ordem legal e pelo próprio Estado na defesa de interesses proprietários. $\mathrm{O}$ historiador inglês observa uma mudança de sentido na própria sociedade em direção a uma postura extremamente individualista ${ }^{12}$ e potestativa na sua relação com as coisas e, enfim, demonstra que os conceitos jurídicos não podem ser afastados do seu chão e do seu tempo.

\section{PROPRIEDADE E HISTÓRIA}

O interessante exemplo retirado de "Senhores e Caçadores" demonstra a necessidade de se analisar com muito cuidado a relação entre as pessoas e as coisas. Quando

11 Conforme explica Bernard Edelman, "A ideologia denuncia-se delineando o seu acto de nascimento. E o seu acto de nascimento é o postular que o homem é naturalmente um sujeito de direito, isto é, um proprietário em potência, visto que é de sua essência apropriar-se da natureza." (EDELMAN, B. $O$ direito captado pela fotografia. Coimbra: Centelho, 1976. p.25).

12 Em passagem muito interessante Gerd Bornheim exprime essa mudança de sentido ao trabalhar com a noção de propriedade privada aos moldes elaborados pela burguesia. Nas palavras de Gerd Bornheim: "Abrevio o tema dizendo que o súdito medieval, o homem subordinado ao rei e ao papa, empenhavam-se em construir as muralhas da cidade e mesmo as do império; o burguês, como que emoldurando os seus procedimentos de autoafirmação, despreocupa-se da cidade e limita-se à construção do muro que protege a sua própria casa." (BORNHEIM, G. O Sujeito e a norma, In: NOVAES, A. Ética. São Paulo: Companhia das Letras, 1992. p. 250). 
se fala em propriedade e de sua regulamentação jurídica é necessário observar que "por trás de uma mesma morfologia geralmente há, em perspectiva histórica, uma muito diversa semântica."13 É necessário ir um pouco além da mera semelhança terminológica das construções jurídicas.

Não é possível esquecer que o direito é um produto histórico ${ }^{14} \mathrm{e}$, por isso, a compreensão das categorias e dos institutos jurídicos, bem como das suas implicações na realidade, não pode estar distanciada do estudo e da reflexão a respeito das diferentes temporalidades e localidades em que foram pensados e idealizados os diferentes direitos. A reflexão sobre direito e propriedade deve estar atenta à realidade, aberta a críticas e consciente do ambiente econômico, político e cultural em que foi constituído. ${ }^{15}$

${ }^{13}$ FONSECA, R. M. A "Lei de Terras" e o advento da propriedade moderna no Brasil, "in": Anuário Mexicano de Historia del Derecho, México: Instituto de Investigaciones Jurídicas Unam n. 17, ano 2005, p.97-112. p. 98.

14 Nas palavras de António Manoel Hespanha: "A História do direito realiza esta missão sublinhando que o direito existe sempre em sociedade e que, seja qual for o modelo usado para descrever as suas relações com os contextos sociais (simbólicos, económicos, etc.), as soluções jurídicas são sempre contingentes em relação a um dado envolvimento (ou ambiente). São, neste sentido, sempre locais." (HESPANHA, A. M. Panorama histórico da cultura jurídica européia. Lisboa: Publicações Europa-América, 1997. p. 15).

15 Nessa linha, conforme sustenta Ricardo Marcelo Fonseca, deve-se entender "a história não apenas como uma 'introdução' ao estudo ou à análise que, após ser utilizada sem critério, não será retomada em nenhum outro momento da pesquisa: a história pode (e deve) atravessar o próprio estudo, constituindo o seu cerne metodológico." (FONSECA, R. M. A história no direito e a verdade no processo: o argumento de Michel Foucault. Genesis, Curitiba, n. ${ }^{\circ} 17$, p.570-585, jul./set. 2000. p. 574).
Essa concepção metodológica depende, entretanto, do que se entende por História e qual o papel da História do Direito no desenvolvimento da pesquisa e da reflexão acadêmica. Orientação importante a ser seguida é dada por Paolo Grossi: “um dos papéis, e certamente não o último, do historiador do direito junto ao operador do direito positivo seja o de servir como sua consciência crítica, revelando como complexo o que na sua visão unilinear poderia parecer simples, rompendo as suas convicções acríticas, relativizando certezas consideradas absolutas, insinuando dúvidas sobre lugares comuns recebidos sem uma adequada confirmação cultural". ${ }^{16}$

A História do Direito não pode ser utilizada para justificar e legitimar simplesmente a propriedade moderna. Entender a propriedade na sua profunda historicidade tem a função de dessacralizar, relativizar o moderno direito "natural" de propriedade e compreender que "aquela" concepção de propriedade corresponde a "uma" forma de propriedade e não "a" única maneira de entender e regular juridicamente a relação entre os homens e

${ }^{16}$ GROSSI, P. Mitologias jurídicas da modernidade. Florianópolis: Fundação Boiteux, 2004, p. 11. A compreensão da História do Direito, no presente trabalho, também parte do entendimento de que a função dessa disciplina, ou como quer Hespanha, "a missão da História do Direito é antes a de problematizar o pressuposto implícito e acrítico das disciplinas dogmáticas, ou seja, o de que o direito dos nossos dias é o racional, o necessário, o definitivo." (HESPANHA, A. M. Panorama histórico..., p. 15). Para uma ampla discussão metodológica sobre a História do Direito, ver a monografia de Mestrado de Ricardo Marcelo Fonseca, da UFPR, intitulada "Direito e História: relações entre concepções de história, historiografia e a história do direito a partir da obra de António Manuel Hespanha". 
as coisas. Trata-se de um trabalho de desmitificação, ${ }^{17}$ perspectiva que "retira o caráter absoluto das certezas de hoje, relativiza-as pondo-as em fricção com certezas diferentes ou opostas experimentadas no passado, desmitifica o presente, garante que sejam analisadas de modo crítico, liberando os fermentos atuais da estática daquilo que é vigente e estipulando o caminho para a construção do futuro." 18

Para percorrer o caminho proposto são necessários alguns cuidados metodológicos na análise historiográfica da propriedade. Nessa linha, as reflexões de Paolo Grossi sobre história do direito de propriedade e demais formas de pertencimento (ou das relações entre as pessoas e as coisas) são fundamentais e devem servir como um norte ao desenvolvimento de toda pesquisa em relação ao tema. Paolo Grossi é conhecido e especialmente reconhecido por suas reflexões sobre a propriedade. Como afirmou o grande jurista espanhol Francisco Tomás y Valiente: "Grossi es el gran historiador de la propiedad."19 Deve-se, observando alguns dos cuidados metodológicos sugeridos e

\footnotetext{
17 Segundo Paolo Grossi, "O historiador, que por profissão é um relativizador e, conseqüentemente, um desmitificador, sente-se no dever de advertir o jurista que um nó como esse pode e deve ser desfeito, e que seu olhar deve ser liberado da lente vinculante colocada diante de seus olhos por duzentos anos de habilíssima propaganda." (GROSSI, Paolo. Mitologias jurídicas da modernidade, Florianópolis: Fundação Boiteux, 2004. p. 12).

18 GROSSI, P. Mitologias jurídicas..., p. 26.

${ }^{19}$ TOMÁS Y VALIENTE, F. Laudatio a Paolo Grossi “in" CAPPELLINI, P. et alii. De la Ilustración al Liberalismo: symposium em honor al profesor Paolo Grossi. Madrid: Centro de estudios constitucionales, 1995. p. 34.
}

desenvolvidos por Paolo Grossi, verificar e evitar os principais "riscos culturais" na análise da propriedade e de sua história.

\section{PESADO CONDICIONAMENTO MONOCULTURAL DA PALAVRA PROPRIEDADE}

O primeiro grande risco cultural ao se trabalhar com a idéia de propriedade, segundo Paolo Grossi, é o pesado condicionamento cultural que a expressão propriedade adquiriu na Modernidade. ${ }^{20} \mathrm{~A}$ referência ao termo propriedade (especialmente privada) carrega, e não é de hoje, um significado muito específico na história, limitado a uma concepção individualista e potestativa da relação entre os homens e os bens.

A palavra propriedade remete habitualmente a uma forma de apropriação dos bens que parte sempre de um sujeito proprietário e de seu poder exclusivo e soberano ${ }^{21}$ sobre as coisas, ou seja, uma perspectiva de propriedade que adquiriu uma posição hegemônica quase que absoluta na Modernidade.

Deve-se tomar cuidado ainda que o termo seja utilizado no plural. Nas palavras de Grossi, "la nostra insegna [La proprietà e le proprietà], pur con tutte le sue pluralizzazioni, porta impresso il richiamo ingombrante a un universo 'proprietario', e proprietà è sempre un minimo di appartenenza, di poteri esclusivi e dispositivi conferiti a un determinato soggetto dall ordine giuridico. Parlare

${ }^{20}$ GROSSI, P. Il dominio e le cose: percezione medievali e moderne dei diritti reali. Milano: Giuffrè, 1992, p.603 e segs. p. 603-609.

21 GROSSI, P. L'inaugurazine della proprietà moderna. Napoli: Guida Editori, 1980, p. 23. 
soltanto di proprietà, anche se al plurale, significa restare ben racchiusi entro la nicchia di una cultura dell appartenenza individuale. E questo è un orizzonte troppo angusto."22

Paolo Grossi, em um trabalho muito interessante intitulado "Un altro modo di possedere", vai demonstrar que na Europa do século XIX, em plena consagração do modelo burguês de apropriação privada, surge com força na consciência jurídica desse século a reflexão a respeito de formas coletivas de propriedade e inúmeras outras relações entre as pessoas e os bens, abalando a monocracia da propriedade individual. Evidentemente que esse "corpo estraneo nell' organismo ottocentesco doveva essere o assorbito o rigettato. E fu rigettato." 23

Além disso, como nos explica esse autor, em inúmeras outras civilizações africanas, asiáticas e até mesmo americanas existem "pianeti giuridici diversi dove non è tanto la terra che appartiene all uomo ma piuttosto l’uomo alla terra, dove l’appropriazione individuale appare invenzione sconosciuta o assetto marginale". ${ }^{24}$ Sistemas profundamente diferentes em que o primado é do objetivo sobre o subjetivo.

Analisando algumas linhas gerais do direito medieval (europeu) e a maneira como a relação entre homens e coisas era compreendida, também se observa que a noção moderna de propriedade, presa ao ideário de um sujeito titular de poderes sobre a coisa, não tinha nenhuma possibilidade de

${ }^{22}$ GROSSI, P. Il dominio e le cose..., p.606.

23 GROSSI, P. Un altro modo di possedere: l'emersione di forme alternative di proprietà alla coscienza giuridica postunitaria. Milano: Giuffrè, 1977. p. 14.

${ }^{24}$ GROSSI, P. Il dominio e le cose..., p.607. existir, pois, a "figura do sujeito proprietário dependendo de uma visão individualista e antropocêntrica - ainda não encontra lugar." 25 O primado é do todo sobre o individual. ${ }^{26}$ Só foi possível o nascimento e o desenvolvimento de uma visão individualista e potestativa de propriedade em um tempo e local em que o indivíduo é a medida e o fundamento de todas as coisas.

Observando os exemplos acima esboçados das propriedades coletivas, das diferentes relações de pertencimento em outras civilizações, que não a moderna civilização européia ocidental, e analisando outros períodos históricos como a Idade Média, é possível concluir que a palavra "proprietà deve essere soltanto un artifizio verbale per indicare la soluzione storica che un ordinamento dà al problema del legame giuridico più intenso fra um soggeto e un bene". ${ }^{27}$ Não é demais alertar: apesar das mesmas palavras ou expressões os sentidos históricos podem ser muito diversos.

\section{O CARÁter ABSOLUTO DO DISCURSO JURÍDICO DA PROPRIEDADE}

Um segundo risco cultural que deve ser evitado no estudo da história do direito de

${ }^{25}$ FONSECA, R. M. A Lei de terras e o advento da propriedade..., p.102-103.

${ }^{26}$ Sobre a civilização medieval, explica Grossi: "A livello sociale non emerge l'individuo, creatura che sarebbe condannata a morte nella sua solitudine in modo non dissimile dalla formica avulsa dal suo formicaio". (GROSSI, P. Dalla società di società alla insularità dello stato fra medievo ed età moderna, Napoli: Istituto Universitario Suor Orsola Benincasa, s/d. p.14).

${ }^{27}$ GROSSI, P. Il dominio e le cose..., p.605-606. 
propriedade é a absolutização da idéia de propriedade nos moldes em que foi pensada na Modernidade, sedimentada sobre as bases do individualismo proprietário. ${ }^{28}$ Segundo Paolo Grossi, "Storicizzare l'archetipo è esigenza ovvia ed elementare per lo storico del diritto". ${ }^{29}$

Ocorre que uma determinada concepção de propriedade, marcada por uma perspectiva profundamente subjetiva da relação entre os homens e as coisas, fruto de uma mudança antropológica radical, passa a ser entendida e tutelada pelo moderno direito estatal como um direito natural por excelência, e a história é utilizada por um certo discurso historiográfico para a sua justificação e legitimação.

Esse procedimento historicista, ${ }^{30}$ que se caracteriza especialmente por trabalhar com o passado de forma linear, causa no mínimo

${ }^{28}$ Individualismo proprietário que não concebe o direito sem a proteção privilegiada da propriedade de matriz individualista, excludente e patrimonialista. Como observa José Antônio Peres Gediel, "A liberdade de apropriação privada de bens assegurada pela lei e garantida pelo Estado passou a atribuir ao proprietário poderes exclusivos de fruição das potencialidades econômicas dos bens apropriados, em oposição aos demais sujeitos." (GEDIEL. J. A. P. Os transplantes de órgãos e a invenção moderna do corpo. Curitiba: Moinho do Verbo, 2000. p. 16).

${ }^{29}$ GROSSI, P. Il dominio e le cose..., p.611.

30 Segundo Ricardo Marcelo: "Em suma, este discurso histórico do direito (que aqui eu chamaria de historicismo jurídico) acaba desempenhando a função de justificar e legitimar o direito de hoje, contribuindo, em certa medida, para imunizá-lo de críticas em prol de uma suposta 'tradição histórica'." (FONSECA, R. M. A história no direito..., p. 573). Deve ser verificado, como demonstra Ricardo Marcelo Fonseca, que do ponto de vista metodológico o historicismo (história tradicional) é uma história positivista, perspectiva também adotada no presente trabalho. (FONSECA, R. M. Direito e história...). dois grandes problemas na reflexão da história do direito de propriedade. Uma primeira distorção decorre da compreensão do passado como um simples prelúdio do presente ou como uma simples continuidade do que se tem hoje, e a propriedade acaba por ser entendida como uma construção praticamente imutável, estática, o que implica em eliminar a historicidade própria do conceito. Uma outra grave distorção, que decorre dessa falsa noção de linearidade, é apresentar o direito moderno de propriedade como fruto da constante evolução das relações sociais, das teorias e dos institutos jurídicos, deixando "claro" a ilusão que os "tempos atuais" são melhores que o passado e a humanidade caminha em direção ao progresso.

A propriedade privada é interiorizada através do procedimento histórico. ${ }^{31} \mathrm{Nas}$ palavras de Paolo Grossi: "La soluzione storica tende a diventare ideologia facendo un clamoroso salto di piani, e il modesto istituto giuridico che è conveniente tutelatore di determinati interessi di ceto e di classe, è sottratto alla relatività del divenire e connotato di assolutezza. L`istituto da coagulo sociale rischia sempre di diventare un modello, la rappresentazione della

${ }^{31}$ Nessa linha de raciocínio vale lembrar a lição de José Reinaldo de lima Lopes : "Quais as mudanças pelas quais passou a propriedade ao longo da história? Especialmente, considerada a tradição ocidental de estudo do direito desde o século XII, quais as diferenças observáveis? Uma primeira intuição pode levar qualquer um à idéia de que propriedade é uma categoria do espírito, uma categoria sempre igual a si mesma. Aí começam as armadilhas. Certamente uma distinção entre meu e teu pode ser universal. Mas a propriedade, como regime jurídico, tem formas muito distintas ao longo da história." (LOPES, J. R. L. O direito na História, p. 401.) 
validità suprema, l’ápice espressivo d’una ricerca del bene sociale." 32 A concepção individualista e potestativa de propriedade é absolutizada e imunizada de qualquer reflexão crítica. A forte propaganda revolucionária burguesa conseguiu naturalizar o que em realidade é histórico.

Deve-se evitar a armadilha de compreender o passado de forma linear, como se tudo fosse uma relação pura e simples de causa e efeito, pois o "estudo linear da história do direito, (que amontoa tudo o que já passou numa superposição harmônica e coerente de institutos jurídicos através do tempo) acaba impondo uma lógica ao passado que em verdade lhe é estranha, ao mesmo tempo em que lança sobre a época pretérita as questões, preocupações, valorações e ansiedades que pertencem ao presente". ${ }^{33}$

Abandonando o discurso historicista, verifica-se que a construção da propriedade como um direito abstrato, individual, praticamente absoluto de usar, gozar e dispor, consagrada no movimento de codificação (especialmente no Código Civil Francês) é uma invenção moderna e não um instituto trans-histórico como "se fosse um diamante que desde sempre foi valioso, e que o tempo, no máximo, teve a função de lapidar com capricho e sabedoria, de modo a transformar essa pedra numa jóia cada vez mais preciosa."34 Relativizar e desmitificar esse pensamento é obrigação do historiador do direito de propriedade.

\footnotetext{
${ }^{32}$ GROSSI, P. Il dominio e le cose..., p.609-610.

${ }^{33}$ FONSECA, R. M. A história no direito..., p. 572.

${ }^{34}$ FONSECA, R. M. A Lei de Terras e o advento da propriedade..., p. 97-98.
}

\section{ABORDAGEM FORMALISTA DO DIREITO DE PROPRIEDADE}

Um outro cuidado metodológico na análise histórica da propriedade e das propriedades é compreender que estas noções e a sua regulação no âmbito do direito não são apenas um conjunto formal de normas e regras devidamente concatenadas. Como explica Grossi, "La proprietà non consisterà mai in una regoletta tecnica ma in una risposta all eterno problema del rapporto fra uomo e cose, della frizione fra mondo dei soggetti e mondo dei fenomeni, e colui che si accinge a ricostruirne la storia, lungi dal cedere a tentazioni isolazionistiche, dovrà, al contrario, tentar di collocarla sempre all interno di uma mentalità e di un sistema fondiario con funzione eminemente interpretativa."35

A compreensão do direito de propriedade como um complexo de regras é resultado de uma armadilha do moderno direito burguês, um direito monopolizado pelo Estado e praticamente reduzido à figura da Lei (primado ou até mesmo exclusividade da Lei sobre todas as outras fontes do direito). $\mathrm{Na}$ civilização jurídica moderna o direito sofre um processo violento de redução e simplificação ao ser colonizado pelo Estado e retirado do espaço plural da sociedade. Grossi denomina esse processo de “absolutismo jurídico". 36

${ }^{35}$ GROSSI, P. Il dominio e le cose..., p.614.

36 GROSSI, P. Assolutimo giuridico e diritto privato, Milano: Giuffrè, 1988. Segundo esse autor, "Assolutismo giuridico significa una civiltà giuridica che perde (o attenua di parecchio) la percezione della complessità; una civiltà giuridica che è divenuta un ordine semplice, estremamente coerente nelle sue 
Nesse direito pós-revolucionário marcado por sua pretensão à totalidade e universalidade, bem como por sua estatização, a forma Código $^{37}$ (o Código no seu modelo moderno) filho do Iluminismo e de inspiração jusnaturalista (racionalista) é o grande símbolo dessa nova mentalidade jurídica e o abrigo privilegiado do sagrado direito de propriedade privada. "O jusnaturalismo vem a desembocar no mais agudo positivismo jurídico, e o Código, mesmo se portador de valores universais, é reduzido à voz do soberano nacional, à lei positiva desse ou daquele Estado." 38

A forma Código tem a pretensão de regular todas as zonas do ordenamento jurídico, especialmente a propriedade. Isso significa dizer que até o final do século XVI o que era regulado e normalizado fora do poder soberano, pela própria sociedade, através de práticas e costumes, passa a ser regulamentado por uma única lei, abstrata e geral. "O drama do planeta moderno consistirá em realizar o processo de absorção de todo o direito na lei, na sua identificação na Lei.". 39 A regulação jurídica das relações entre as pessoas e as coisas é atingida diretamente por essa nova racionalidade.

O Código (forma código) se caracteriza por uma tipicidade inconfundível: i) tende a

linee essenziali, forte di una sua logica rigorosa, ma troppo poco sensibile al divenire e, soprattutto, al mutamento." (p. 7).

37 Para uma reflexão crítica e muito interessante sobre o papel do Código na Modernidade, verificar CAPPELLINI, P.; SORDI, B. Codici: una riflessione di fine millennio. Milano: Giuffrè. 2000.

38 GROSSI, P. Mitologias jurídicas..., p. 114.

39 GROSSI, P. Mitologias jurídicas..., p. 50. ser uma fonte unitária (forte monismo jurídico - em que a lei proveniente do Estado é a fonte quase que exclusiva do direito); ii) tende a ser fonte completa (toda a experiência, toda a realidade são reduzidos a um sistema de regras jurídicas); iii) tende a ser fonte exclusiva (o direito estatal como a única fonte legítima de direito, materializada no Código). "Como norma que presume prender a complexidade do social em um sistema fechado, o Código, toda codificação, somente pode traduzir-se em uma operação drasticamente redutiva (...)". ${ }^{40}$

Esse processo de codificação é fruto de um determinado momento histórico marcado pela hegemonia da burguesia em sociedade, pelo desenvolvimento do capitalismo e do liberalismo econômico, pela constituição dos Estados Liberais, entre outros fatores. O Direito, nesse mundo moderno (especialmente com a codificação francesa), passa a ser muito mais loi e sempre menos droit. ${ }^{41}$ Não é sem razão que as fontes legislativas e sua história assumem fundamental importância de legitimação do atual sistema de apropriação.

\section{HISTÓRIA AGRÁRIA, CONCATENAÇÃO DOS FATOS E AUTONOMIA DA DIMENSÃO JURÍDICA}

Um outro grave risco cultural é a perda da especificidade do fenômeno jurídico, muitas vezes diluído pela chamada "storia agraria, per la storia cioè del fatto técnico ed economico coltivazione-produzione". ${ }^{42}$

\footnotetext{
40 GROSSI, P. Mitologias jurídicas..., p. 125

41 GROSSI, P. Mitologias jurídicas..., p. 115.

${ }^{42}$ GROSSI, P. Il dominio e le cose..., p. 617.
} 
O historiador do direito não pode ficar preso ao formalismo, que compreende o direito como um simples conjunto de fontes formais, mas também deve evitar o equívoco oposto, ou seja, não deve desprezar o fenômeno jurídico nas suas profundas peculiaridades e o papel fundamental desempenhado pelo direito na ordenação e constituição da realidade.

A história agrária tem o mérito de libertar o discurso historiográfico sobre o direito de propriedade da simplificação dos esquemas formais de análise, quebrando com a "pureza" das construções jurídicas, mas corre o risco de se perder em uma simples concatenação de fatos econômicos e observação de dados técnico-agrários. Um amontoado de fatos, bem como a confusão entre a dimensão jurídica e a econômica não auxilia na compreensão das relações entre os homens e os bens e a sua ordenação.

$\mathrm{O}$ se quer, nesse ponto, é evitar que a análise do direito de propriedade ao longo da história perca a sua autonomia. Para isso, é importante considerar a observação de Paolo Grossi sobre a história agrária: "Un rilevante punto di metodo che emerge è lesigenza di un ricorso critico al serbatoio della storia agraria. Non creda lo storico del diritto di trovarvi la panacea capace di esaudire le sue aspirazioni. Poiché proprietà è soprattutto mentalità, il cumulo di dati tecnico-agrari può, in determinati contesti, fungere anzi, o per contrasto o per estraneità o per non-coincidenza rispetto a quella, da elemento storiograficamente fuorviante."43

${ }^{43}$ GROSSI, P. Il dominio e le cose..., p. 620.
O contesto econômico-agrário, em que as relações de pertencimento são pensadas, é muito importante, mas por si só não é suficiente para explicar o fenômeno jurídico. Como explica Paolo Grossi, "Fare delle proprietà un elemento del paesaggio storico grazie agli strumenti della storia agraria è dunque meritorio purché si eviti il rischio di disperdere nella varietà del paesaggio la limpidezza della dimensione giuridica". ${ }^{4}$ $\mathrm{O}$ historiador do direito deve estar atento às especificidades do seu ofício, tomando o cuidado para não identificar o direito e o seu papel na sociedade apenas como um reflexo de um determinado contexto econômico, de uma infra-estrutura.

O exemplo, analisado por Thompson em “Senhores e Caçadores", é muito interessante porque demonstra, em certa medida, o papel fundamental exercido pelo direito, ou por uma concepção de direito que naquele momento começava a ser identificado com a lei, na Inglaterra do século XVIII e XIX. Uma função desempenhada pela "Lei Negra" na mudança de concepções jurídicas e de construção da própria mentalidade moderna individualista e proprietária. Enfim, nas palavras do próprio historiador (não propriamente do direito), E. P. Thompson, "O direito importa, e é por isso que nos incomodamos com toda essa história."45

\section{DIREITO E PROPRIEDADE COMO MENTALIDADES}

Outro cuidado metodológico fundamental é compreender que a "proprietà è, per queste

\footnotetext{
44 GROSSI, P. Il dominio e le cose..., p. 624.

45 THOMPSON, E. P. Senhores e Caçadores...,
} p. 359 . 
insopprimibili radici, più di ogni altro istituto, mentalità, anzi mentalità profonda."46 Mentalidade compreendida como "quel complesso di valori circolanti in un' area spaziale e temporale capace per la sua vitalità di superare la diaspora di fatti ed episodi sparsi e di costituire il tessuto connettivo nascosto e costante di quell area, ed è pertanto da cogliersi come realtà unitiva" ${ }^{47}$ Propriedade e o próprio direito são mentalidades profundas.

Como já foi ressaltado, o direito é um produto eminentemente histórico, imanente à sociedade e que pertence a uma dimensão civilizatória, pois, participa concretamente na vida das pessoas. Segundo Grossi, não há como conceber o direito sem compreender a sua dimensão profundamente humana e social, é produto dos homens e só existe em relação, mas é também organização (autoorganização), pois é o direito que organiza o caos social e estrutura a vida em sociedade.

Não se confunde simplesmente com ordem imperativa ou com coação e, por isso, é ordenamento, um ordenamento observado que encontra validade no seio e nos valores de uma determinada sociedade. ${ }^{48}$

O direito é uma dimensão bastante profunda de uma determinada sociedade e a reflexão sobre as diferentes relações de pertencimento, envolvendo as pessoas e as coisas, não pode deixar de considerar esse dado fundamental.

O percurso histórico do conceito moderno de propriedade é bastante longo, alguns de seus alicerces são encontrados em

${ }^{46}$ GROSSI, P. Il dominio e le cose..., p. 625.

${ }^{47}$ GROSSI, P. Il dominio e le cose..., p. 624.

48 GROSSI, P. Primeira lição sobre direito (trad. Ricardo Marcelo). Rio de Janeiro: Forense, 2006. momentos históricos muito distantes, embora essa noção só tenha adquirido toda a sua força no mundo moderno apenas no século XIX. Como ensina Grossi, para entender a construção da propriedade moderna é necessário revisitar, no mínimo, a teologia voluntarista dos séculos XIV e XV, ${ }^{49}$ estudar o pensamento da Segunda Escolástica espanhola, ${ }^{50}$ analisar o individualismo possessivo dos séculos XVII e XVIII, para se chegar então às cartas constitucionais do século XVIII e dos códigos do século XIX. É necessário, portanto, compreender que propriedade é antes de tudo mentalidade.

\section{UMA PROFUNDA DESCONTINUIDADE}

Considerar a ruptura existente entre os diferentes modelos de pertencimento é uma precaução metodológica sem a qual não é possível trabalhar com o tema da propriedade. Deve-se observar "che la storia della appartenenza e dei rapporti giuridici sulle cose è necessariamente segnata da una profonda discontinuità; necessariamente, giacché proprietà è soprattutto mentalità"(...)“Tante 'proprietà' - per così dire - quante sono le esperienze giuridiche succedutesi nel tempo.". ${ }^{1}$ A história das relações entre os

49 Verificar: GROSSI, P. Usus facti: la nozione di proprietà nella inaugurazione dell'età nuova, "in" Quaderni Fiorentini per la Storia del Pensiero Giuridico Moderno, I (1972).

50 Verificar: GROSSI, P. La proprietà nel sistema privatistico della Seconda Scolastica, "in" GROSSI, Paolo (a cura di). La seconda scolastica nella formazione del diritto privato moderno. Milano: Giuffè, 1973, p. 117 e segs. Verificar também: VILLEY, M. A formação do pensamento jurídico moderno, São Paulo: Martins Fontes, 2005.

${ }^{51}$ GROSSI, P. Il dominio e le cose..., p. 630-631. 
homens e os bens é uma história marcada por diferentes experiências jurídicas constituídas em variados contextos e culturas. Identificar as suas diferenças, peculiaridades e rupturas é tarefa do historiador.

Na obra de Thompson, conforme observado, a descontinuidade das concepções de pertencimento é bem observada. Um novo direito de propriedade que surge com muita força, apoiado pelas forças da burguesia emergente e tutelado pelo moderno direito monista e estatal, sufocando inúmeras outras formas de relação de sobrevivência entre aquelas pessoas e as suas florestas.

A concepção equivocada que acaba identificando o passado com o presente ao eliminar a idéia de ruptura é sentida especialmente na doutrina jurídica tradicional em matéria de propriedade. Basta observar a constante preocupação da maior parte dos autores de manuais dogmáticos com os precedentes históricos, ${ }^{52}$ Por esse procedimento de utilização dos precedentes, os "institutos contemporâneos são assim 'naturalizados' e tidos como resultado da tradição". 53

52 Nas palavras de Hespanha: "Os historiadores do direito fazem, freqüentemente, uma leitura do direito passado na perspectiva do actual, procurando lá os 'prenúncios', as 'raízes' dos conceitos, dos princípios e das instituições actuais. Por exemplo (...) se estudam a propriedade, pegam na história do dominium sobre as coisas, conceito que, em algumas definições romanas (ius utendi ac abutendi), parece corresponder à actual propriedade individualista (...). [Entretanto,] um estudo da lógica originária do conceito, bem como da sua integração no seu contexto conceitual ou institucional de então, mostraria que, se se respeitar a autonomia do conceito histórico, este não corresponde, de forma alguma, ao actual. (HESPANHA, A. M. Panorama histórico..., p.73).

${ }^{53}$ FONSECA, R. M. Direito e história..., p. 36.
Na observação de Ricardo Marcelo Fonseca, "este era o mote da Escola Histórica Alemã do século XIX, quando o 'argumento histórico' tem um papel dogmático fundamental: por um lado revelar o direito proveniente do 'espírito do povo' ('Volksgeist'), inserido em suas tradições históricas, e por outro proteger o direito contra as inovações arbitrárias e desviadas do verdadeiro "passado histórico", 54 Buscam no direito romano o fundamento para a defesa de suas idéias e concepções, utilizando uma forte argumentação que se sustenta em toda a tradição dos textos antigos. O discurso histórico novamente é apropriado pela lógica do presente.

Ocorre que a utilização corrente dos precedentes, muito mais do que explicar alguma coisa, leva o leitor (intencionalmente ou não) a acreditar que o que se estuda em matéria de direito de propriedade, atualmente, é algo que desde sempre vem sendo tratado, ou seja, as preocupações presentes são as mesmas do passado mesmo que existam mais de dois mil anos de diferença separando essas civilizações e os seus sistemas de pensamento.

António M. Hespanha narra um exemplo emblemático dessa equivocada "necessidade", mas com intenção legitimadora, de vinculação entre o passado e o presente em matéria de propriedade. Segundo o autor, "quando elaborava o borrão da encíclica Quadragesimo anno, o Cardeal De Gasperi, preocupado em encontrar uma fundamentação histórica e tradicional para a doutrina da Igreja de defesa da propriedade privada contra os erros do comunismo, saudara com uma entusiástica anotação $<<$ Ecco il diritto di proprietà! >>

${ }^{54}$ FONSECA, R. M. Direito e história..., p. 36. 
um passo de $\mathrm{S}$. Tomás onde se falava de dominium no sentido não exclusivista e não individualista que o termo então tinha. [Este] É um exemplo de como as preocupações contextuais agem sobre a leitura. Mas, geralmente, os processos de contextualização social da leitura são menos directos." ${ }^{55}$

Deve-se, portanto, evitar o grave equívoco de identificar nas relações de pertencimento da Antigüidade, especialmente aquelas reguladas pelo direito romano, ou em qualquer outro período histórico anterior à Modernidade o simples reflexo do presente. ${ }^{56}$ A propriedade privada nos moldes como foi constituída pelo pensamento jurídico moderno, especialmente pelas suas características de simplicidade e abstração, é uma grande novidade do ponto de vista historiográfico. Prova do que se está

55 HESPANHA, A. M. Panorama histórico..., p.46-47, nota $\mathrm{n}^{\circ} 43$.

56 Como explica José Reinaldo de Lima LOPES, a "visão geral do direito antigo, incluindo o direito romano, serve para marcar as essenciais diferenças entre o que hoje chamamos direito e o que foi o direito de civilizações já desaparecidas. De fato, de alguma forma, inseridos que estamos na órbita da civilização ocidental, é claro que a herança romana nos chegou, assim como algo da herança grega. Apesar disso é bom lembrar que o direito romano só nos chega porque foi 'redescoberto' e verdadeiramente 'reinventado' duas vezes na Europa ocidental: a primeira vez nos séculos XII a XV e a segunda vez no século XIX, respectivamente pelos juristas da universidade medieval, glosadores e comentadores, e pelos professores alemães que tentavam a unificação nacional. (...) Nestes termos, a redescoberta do direito romano nunca veio acompanhada das mesmas instituições ou ambiente cultural originais e aqui será bom marcar estas diferenças." (LOPES, J. R. L. O Direito na história..., p. 29 e 30.). Uma análise interessante sobre as particularidades das idéias de propriedade no direito romano em relação ao direito moderno é verificada na obra de Henrique da Silva Seixas Meireles: "Marx e o Direito Civil (para a crítica histórica do "paradigma civilístico')". sustentando são as inúmeras relações de pertencimento existentes na civilização medieval ordenadas pelo direito.

A experiência jurídica medieval, como explica Paolo Grossi, é bastante típica e pode ser entendida a partir de algumas de suas principais características: i) é um direito que se desenvolve no vazio relativo do poder político - o direito não é identificado como uma manifestação do poder político, pois não é possível, ainda, falar de Estado e soberania (no sentido moderno dos termos) naquele período; ii) verifica-se uma relativa indiferença do poder político pelo direito que permite que este se crie e se desenvolva no coração da sociedade; iii) um forte pluralismo observado nesse direito medieval; iv) a sua factualidade - um direito que se dá e se verifica na práxis; v) a sua historicidade construção histórica e não ato de império ou poder de um príncipe ou soberano; vi) um direito bastante rico e complexo sem pretensões de simplificação e abstração como o direito moderno; vii) reicentrismo dessa experiência jurídica - baseada nas coisas e na natureza destas e não na idéia de um sujeito titular de direitos; ix) além do reicentrismo o comunitarismo - a comunidade como a cédula vital - não existe ainda o "indivíduo" nessa sociedade e o direito é em larga medida determinado pela "perfeição" da comunidade e o papel que cada um exerce nesse todo. x) direito baseado na noção de "ordem" existente no mundo que leva a pluralidade à unidade; xi) uma presença da igreja na constituição dessa mentalidade jurídica; xii) um direito marcado pela práxis. ${ }^{57}$

57 GROSSI, P. L'Ordine giuridico medievale. Roma-Bari: Laterza, 1995. 
Especificamente em matéria de pertencimento verifica-se no mundo medieval uma civilização profundamente possessória, com um número muito amplo e aberto de ordens jurídicas atípicas, em que prevalece o primado do todo sobre o individual, ${ }^{58}$ numa ordem "profundamente ligada às coisas, no interior das quais se insere o indivíduo operante, em meio a uma visão de mundo profundamente reicêntrica e claramente objetiva da ordem natural e social.". 59

É o reino da efetividade, da prevalência de situações efetivas de utilização, gozo e exercício de acordo com as múltiplas possibilidades e potencialidades das coisas. Não existe, ainda, uma relação de dependência ou de domínio do sujeito sobre a coisa. A propriedade moderna na sua simplicidade e abstração não é encontrada na civilização medieval.

Uma última observação. Falar de ruptura remete para uma outra ordem de precauções metodológicas que o historiador do direito deve observar para não cometer graves equívocos. Não se pode esquecer que "a experiência histórica brasileira é muito diversa daquela européia e por isso devemos tomar cuidado ao importar à realidade lusoamericana as categorias utilizadas pelos historiadores que se voltam ao velho mundo."60 São planetas jurídicos muito

58 Nas palavras de Grossi: "perfezione della comunità e imperfezione del singolo." (GROSSI, P. L'Ordine giuridico medievale..., p. 196).

${ }^{59}$ FONSECA, R. M. A "Lei de Terras" e o advento da propriedade..., p. 101-102.

${ }^{60}$ FONSECA, R. M. A "Lei de Terras" e o advento da propriedade..., p. 98-99. Um bom exemplo é o conceito de feudalismo, nas palavras de Ricardo Fonseca, no mesmo texto citado, "O conceito de diferentes com histórias bastante diversas que devem ser contadas.

\section{REFERÊNCIAS}

BORNHEIM, G. O sujeito e a norma. In: NOVAES, A. Ética. São Paulo: Companhia das Letras, 1992.

CAPPELLINI, P.; SORDI, B. Codici: una riflessione di fine millennio. Milano: Giuffrè. 2000.

EDELMAN. B. O direito captado pela fotografia. Coimbra: Centelho, 1976.

FONSECA, R. M. A "Lei de Terras" e o advento da propriedade moderna no Brasil. "in": Anuário Mexicano de Historia del Derecho, México: Instituto de Investigaciones Jurídicas Unam n. 17, ano 2005, p.97-112.

FONSECA, R. M. Direito e história: relações entre concepção de história, historiografia e a história do direito a partir da obra de António Manuel Hespanha. Curitiba, 1997, 118 f., Dissertação (Mestrado em Direito), Setor de Ciências Jurídicas, Universidade Federal do Paraná.

FONSECA, R. M. A história no direito e a verdade no processo: o argumento de Michel Foucault. Genesis, Curitiba, n. ${ }^{\circ}$ 17, p.570-585, jul./set. 2000.

GEDIEL. J. A. P. Os transplantes de órgãos e a invenção moderna do corpo. Curitiba: Moinho do Verbo, 2000.

GROSSI, P. Assolutismo giuridico e diritto privato. Milano: Giuffrè, 1988.

feudalismo, por exemplo, é problemático e não funcional quando voltado à realidade colonial brasileira, já que todo o projeto de colonização fazia parte de um processo de expansão comercial que era próprio do início do capitalismo". Uma obra de história do direito brasileiro muito interessante, que procura tratar as relações de pertencimento no Brasil considerando as suas peculiaridades e diferenças, é o livro: VARELA, L. B. Das Sesmarias à propriedade moderna: um estudo de história do direito brasileiro. Rio de Janeiro: Renovar. 2005. 
GROSSI, P. Il dominio e le cose: percezione medievali e moderne dei diritti reali. Milano: Giuffrè, 1992, p.603 e segs. p. 2-4.

GROSSI, P. Dalla società di società alla insularità dello stato fra medievo ed età moderna, Napoli: Istituto Universitario Suor Orsola Benincasa, s/d.

GROSSI, P. La proprietà nel sistema privatistico della Seconda Scolastica, "in" GROSSI, P. (a cura di). La seconda scolastica nella formazione del diritto privato moderno. Milano: Giuffè, 1973

GROSSI, P. L'inaugurazine della proprietà moderna. Napoli: Guida Editori, 1980.

GROSSI, P. L'Ordine giuridico medievale. 11.ed., Roma-Bari: Laterza, 1995.

GROSSI, P. Mitologias jurídicas da modernidade. Florianópolis: Fundação Boiteux, 2004.

GROSSI, P. Primeira lição sobre direito (trad. Ricardo Marcelo Fonseca), Rio de Janeiro: Forense, 2006.

GROSSI, P. Un Altro Modo di Possedere: l'emersione di forme alternative di proprietà alla coscienza giuridica postunitaria, Milano: Giuffrè, 1977.
GROSSI, P. Usus facti: la nozione di proprietà nella inaugurazione dell'età nuova, "in" Quaderni Fiorentini per la Storia del Pensiero Giuridico Moderno, I (1972).

TOMÁS Y VALIENTE, F. Laudatio a Paolo Grossi “in” CAPPELLINI, P. et alii. De la Ilustración al Liberalismo: symposium em honor al professor Paolo Grossi. Madrid: Centro de estudios constitucionales, 1995.

HESPANHA, A. M. Panorama histórico da cultura jurídica européia. Lisboa: Publicações Europa-América, 1997.

LOPES, J. R. L. O direito na história: lições introdutórias. São Paulo: Max Limonad, 2000.

MEIRELES, H. S. S. Marx e o direito civil (para a crítica histórica do 'paradigma civilístico'). Coimbra: Almedina, 1990.

THOMPSON, E. P. Senhores e Caçadores. 2.ed. Rio de Janeiro: Paz e Terra, 1989.

VARELA, L. B. Das Sesmarias à propriedade moderna: um estudo de história do direito brasileiro. Rio de Janeiro: Renovar. 2005.

VILLEY, M. A formação do pensamento jurídico moderno. São Paulo: Martins Fontes, 2005. 